\title{
NOTE
}

\section{In Vitro Assessment of the Cytotoxicity of Anti-allergic Eye Drops Using 5 Cultured Corneal and Conjunctival Cell Lines}

\author{
${\text { Masahiko Ayaki }{ }^{1 *}, \text { Atsuo Iwasawa }^{2} \text {, Shigeo Yaguchi }{ }^{3} \text { and Ryohei Koide }}^{3}$ \\ ${ }^{1}$ Department of Ophthalmology, Saitama National Hospital (2-1 Suwa, Wako, Saitama 351-0102, JAPAN), \\ ${ }^{2}$ Life Particle Interaction Engineering Creation, New Industry Creation Hatchery Center, Tohoku University (6-6-10 Aramaki-Aoba, Aoba, Sendai, \\ Miyagi 980-8579, JAPAN), \\ ${ }^{3}$ Department of Ophthalmology, Showa University School of Medicine (1-5-8 Hatanodai, Shinagawa, Tokyo 142-8666, JAPAN)
}

\begin{abstract}
The aim of this study was to evaluate the cytotoxicity of anti-allergic eye drops for human corneal endothelial cells (HCEC) and commercially available ocular surface cells. A primary HCEC culture was derived from human eye bank specimens. SIRC (rabbit corneal epithelium), BCE C/D-1b (bovine corneal epithelial cells), RC-1 (rabbit corneal epithelium), and Chang (human conjunctival cells) were obtained commercially. The WST-1 assay was used to measure HCEC viability, and the viability of other cells was measured using the MTT assay. Cells were treated with 7 commercially available anti-allergic eye drops for $48 \mathrm{~h}$ and cell viability was measured and calculated as a percentage of control. The degree of toxicity for each eye-drop solution was based on the cell viability score (CVS). HCECs treated with a 1000-fold dilution of the eye-drop solution had a viability score of $67 \%$ for Rizaben and $\geq 80 \%$ for the other solutions with Zepelin being the least toxic. Cell viability in response to eye-drop solutions preserved with benzalkonium chloride (BAK) was dependent on the concentration of the drug solution and exposure time. Treatment of ocular surface cells with a 20-fold dilution of the eye-drop solution resulted in the following order of cell viability as determined by their CVS: Zepelin $>$ Ketas $=$ Zaditen $\geq$ Tramelas $\mathbf{P F}=$ Patanol $\geq$ Rizaben $\geq$ Livostin. This order was similar to that observed for HCECs, and cell viability was found to be concentration-dependent. Based on the penetration of the drug into eye tissues, HCECs are only likely to be pharmaceutically damaging in rare cases. Epithelial cell viability depends primarily on the concentration of BAK rather than on the action of the active component in the eye-drop solution. CVS values were useful for comparison of toxicity.
\end{abstract}

Key words: benzalkonium chloride, toxicity, eye drop, preservative, eye, cell viability score

\section{INTRODUCTION}

Patients with seasonal and perennial allergic conjunctivitis typically use anti-allergic eye drops either for several months in a year or continuously throughout the year. There are some concerns over the long-term side effects of these eye drops because their pharmaceutical action includes the suppression of cellular activity in allergic reactions. The adverse effects of eye drops on ocular surfaces have been discussed ${ }^{1)}$, and there is a consensus that the preservatives present in the eye drops play a major role in these adverse effects ${ }^{2)}$. Previously, we reported on the ocu- lar surface cell toxicity of anti-allergic eye drops ${ }^{3)}$. We compared the different drugs used in these treatments with respect to their benzalkonium chloride (BAK) concentration and drug action over a short exposure period (10, 30, and $60 \mathrm{~min}$ ). The cell viability score (CVS) of each drug was determined and was found to provide a useful basis for

Abbreviations: HCEC, human corneal endothelial cells; BAK, benzalkonium chloride; CVS, cell viability score; $\mathrm{CB}$, chlorobutanol; $\mathrm{PP}$, propylparahydroxybenzoate; PM, methylparahydroxybenzoate; IR, Inhibitor of the release of histamine from the mast cell; HRB, histamine $\mathrm{H}_{1}$ receptor blocker.

\footnotetext{
* Correspondence to: Masahiko Ayaki, Department of Ophthalmology, Saitama National Hospital, 2-1 Suwa, Wako city, Saitama 351-0102, JAPAN

E-mail: mayaki@olive.ocn.ne.jp

Accepted September 2, 2010 (received for review July 22, 2010)

Journal of Oleo Science ISSN 1345-8957 print / ISSN 1347-3352 online

http://www.jstage.jst.go.jp/browse/jos/
} 
comparison of the toxicity of different treatments. The effect of anti-allergic eye drops on cultured human corneal endothelial cells (HCECs) has been investigated only for the drug Cromoglicate ${ }^{4}$. There is a risk of developing bullous keratopathy after intraocular surgery but the effect of long-term usage of anti-allergic eye drops on the development of this condition remains unknown. Even though mitotic activity of HCECs is low, they regulate water transport in the cornea, and a reduction or loss in this activity leads to severe corneal edema and loss of vision.

In the present study, we evaluated the cytotoxic effects of anti-allergic eye drop exposure on corneal endothelial cells for $48 \mathrm{~h}$ in vitro using primary HCEC cultures derived from human eye bank specimens, as well as 4 commercially available ocular surface cell lines to serve as reference cells.

\section{EXPERIMENTAL PROCEDURES}

\subsection{Commercial eye drops and cell culture}

The drugs evaluated in the present study are listed in Table 1 and Fig. 1. Zepelin and Tramelas PF are BAK-free.

A primary HCEC culture was derived from human eye bank specimens distributed by SightLife (Seattle, WA, USA). This research was approved by the Institutional Review Board of Showa University Fujigaoka Hospital. A cor-

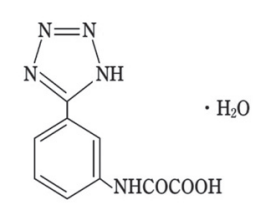

Acitazanolast Hydrate $\left(\right.$ Zepelin $\left.{ }^{R}\right)$
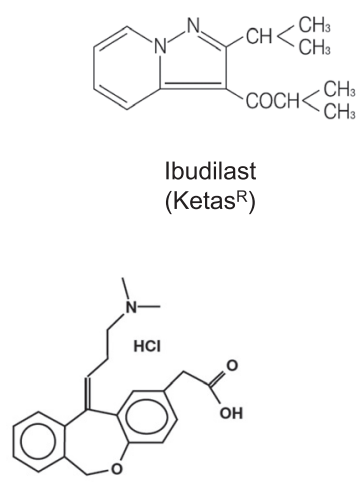

Olopatadine (PatanolR)

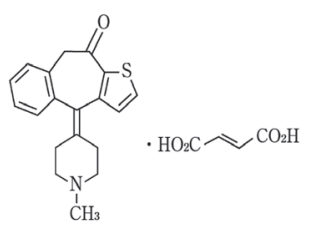

KetotifenFumarate

$\left(\right.$ Zaditen $\left.^{R}\right)$

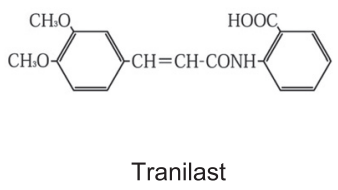

$\left(\right.$ Rizaben $^{R}$, Tramelas ${ }^{R}$ )
Fig. 1 Chemical structure of the drugs

Table 1 Anti-allergic eye drops evaluated in the present study.

\begin{tabular}{|c|c|c|c|c|c|}
\hline $\begin{array}{c}\text { Active } \\
\text { component }\end{array}$ & Trade name & Preservative & Action & ${ }^{*}$ CVS50 & $* *$ CVS40/80 \\
\hline $\begin{array}{l}\text { Acitazanolast } \\
(0.1 \%)\end{array}$ & Zepelin (Wakamoto, Tokyo, Japan) & $\begin{array}{l}\text { CB } 0.25 \%, \\
\text { PM. } 0.026 \% \text {, } \\
\text { PP } 0.014 \%\end{array}$ & IR & 4 & $+3(3-0)$ \\
\hline $\begin{array}{l}\text { Ketotifen } \\
(0.05 \%)\end{array}$ & Zaditen (Novartis, Tokyo, Japan) & BAK $0.005 \%$ & $\begin{array}{c}\text { IR and } \\
\text { HRB }\end{array}$ & 3 & $-1(0-1)$ \\
\hline $\begin{array}{l}\text { Ibudilast } \\
(0.01 \%)\end{array}$ & Ketas (Senju, Osaka, Japan) & BAK $0.005 \%$ & IR & 3 & $-1(0-1)$ \\
\hline $\begin{array}{l}\text { Olopatadine } \\
(0.1 \%)\end{array}$ & Patanol (Alcon Fort Worth, TX, USA ) & BAK $0.01 \%$ & $\begin{array}{c}\text { IR and } \\
\text { HRB }\end{array}$ & 2 & $-1(0-1)$ \\
\hline $\begin{array}{l}\text { Tranilast } \\
(0.1 \%)\end{array}$ & Tramelas PF (Nitten, Nagoya, Japan) & none & IR & 2 & $-2(0-2)$ \\
\hline $\begin{array}{l}\text { Tranilast } \\
(0.1 \%)\end{array}$ & Rizaben (Kissei, Matsumoto, Japan) & BAK $0.005 \%$ & IR & 1 & $-3(0-3)$ \\
\hline $\begin{array}{l}\text { Levocabastine } \\
(0.025 \%)\end{array}$ & Livostin (Santen, Osaka, Japan) & BAK $0.015 \%$ & HRB & 0 & $-4(0-4)$ \\
\hline
\end{tabular}

BAK, benzalkonium chloride; CB, chlorobutanol; PP, propylparahydroxybenzoate; PM, methylparahydroxybenzoate; IR, Inhibitor of the release of histamine from the mast cell; $\mathrm{HRB}$, histamine $\mathrm{H}_{1}$ receptor blocker; CVS, cell viability score. ${ }^{*}$ CVS50 is determined as the number of experiment for viability value in 20 -fold diluted solution $\geq 50 \%$. ${ }^{* *}$ CVS40/80 = (number of experiment for viability value in 20 -fold diluted solution $>80 \%$ ) - (number of experiment for viability value in 20 -fold diluted solution $<40 \%$ ). 
neal button was excised from an eyeball and HCECs were peeled off the central area of the posterior corneal surface. Cells were cultured in Dulbecco's Modified Eagle Medium containing $15 \%$ fetal bovine serum, $2 \mathrm{ng} / \mathrm{mL}$ epidermal growth factor (Austral Biologicals, CA, USA), $30 \mathrm{mg} / \mathrm{L}$ L-glutamine (Wako Pure Biochemicals, Osaka, Japan), Gibco 15240-062 Antibiotic-Antimyotic liquid (Invitrogen, CA, USA). Culture dishes were coated with type IV collagen (BD BioCoat, BD Bioscience, USA) and incubated at $37^{\circ} \mathrm{C}$ in $5 \% \mathrm{CO}_{2}$. Culture media was changed every 3 days. Cell numbers reached sufficient levels for assays after approximately 2 months of culture with 3 passages. Commercially available cell lines included SIRC (rabbit corneal epithelium, ATCC CCL-60, distributed by ATCC; American Type Culture Collection, Manassas, VA, USA), BCE C/D-1b (bovine corneal epithelial cells, JCRB-9129, distributed by Health Science Research Resource Bank, Osaka, Japan), RC-1 (rabbit corneal epithelium, JCRB-0246), and Chang conjunctiva (human conjunctival cells, ATCC CCL-20.2). These cell lines were cultured according to standard protocols provided by the distributor.

\subsection{Cytotoxicity assays}

A $100 \mu \mathrm{L}$ aliquot of media containing approximately $2 \times$ $10^{4}$ cells was harvested from a 96 well microplate $\left(\mathrm{NUNC}^{\mathrm{TM}}\right.$ 167008, Thermo Fisher Scientific, Denmark) and incubated for $2 \mathrm{~d}$. Dilutions of the different test eye drops were made up in $10 \mu \mathrm{L}$ of growth media and added to the cells in culture. HCEC viability was measured following exposure of the cells to eye drop dilutions for $2 \mathrm{~d}$ using the WST-1 (4[3-(4-iodophenyl)-2- (4-nitrophenyl) 2H-5-tetrazolio ] -1,3-benzene disulfonate; Dojindo Laboratories, Kumamoto, Japan $)^{5)}$ assay. Epithelial cells were exposed to the test solution for 10, 30, or 60 min whereupon the medium was replaced with fresh medium, and the cells were incubated for another $48 \mathrm{~h}$. Cell viability was measured using the MTT (3- (4,5-dimethylthiazol-2-yl)-2,5-diphenyl tetrazolium bromide, Sigma $)^{6)}$ assay, and the resulting absorbance was read on a spectrophotometer (Benchmark microplate reader, Bio-Rad, Hercules, CA, USA). The viability of cells in test solutions was calculated as a percentage of control cell viability in media only. Experiments were repeated from 8 to 16 times, and results are presented as the mean $+/-$ standard deviation. Statistical analysis using the student's $t$-test was performed using Microsoft Excel (Tokyo, Japan).

\subsection{Comparison of cell viability by CVS}

The results of cell viability were expressed as a CVS, which is similar to the LD50 (i.e., lethal dose of a toxic substance required to kill half the members of a tested population) and $\mathrm{MIC}_{50}$ (i.e., the minimum inhibitory concentration of a drug required to inhibit the growth of 50\% of organisms). The CVS50 was determined for a 20 -fold di- lution of each solution as the number of measurement for viability value $\geq 50 \%$. The CVS40/80 was calculated in 20 -fold diluted solution as follows: CVS40/80 $=$ (number of measurement for viability value $>80 \%$ ) - (number of measurement for viability value $<40 \%)$. The CVS system is subject to change according to the test solution, cell line, toxicological methods, and other factors. In the present study, the reasons for using the measurements in 20-fold dilution for CVSs include that differences between the solutions were most evident in 20-fold dilution and it was a common cencentration to compare the present and previous results. We have used CVS in prior studies ${ }^{7-10)}$ and have found it to be useful in qualification and comparison of drug toxicity.

\section{RESULTS AND DISCUSSION}

Our assessment of eye-drop toxicity using 4 ocular surface cell lines revealed that Zepelin was the least toxic and Livostin was the most toxic (Fig. 2) and that cell viability was concentration dependent. Results are expressed as CVSs at a 20-fold dilution with full score of 4 (= one concentration, one exposure time, one assay, 4 cell lines) (Table 1). Using CVS50 and CVS40/80 as indicators of cytotoxicity, the order of cell viability after exposure to different eye drops (concentration of BAK, CVS50, and CVS 40/80) was as follows: Zepelin (zero, 4, 3) > Ketas $(0.005 \%, 3,-1)=$ Zaditen $(0.005 \%, 3,-1) \geq$ Tramelas PF $($ zero, $2,-2)=$ Patanol $(0.01 \%, 2,-1) \geq$ Rizaben $(0.005 \%, 1,-3) \geq$ Livostin $(0.015 \%, 0,-4)$. The order of cell viability after treatment generally agreed with the solution BAK concentration with the exception of tranilast containing Rizaben and Tramelas PF. It is notable that the order of cell viability for 20-fold diluted solutions was different among cell lines. Therefore, our recommendation for general evaluation of eye-drop solutions is to consider (1) CVSs for multiple (2 or more cell lines or concentrations) conditions and (2) both CVS50 and CVS40/80. We confirmed the order of CVS with all of 4 concentrations (full score $=16)$ and it was the same as above; Zepelin (16 for CVS50, 14 for CVS40/80) $>\operatorname{Ketas}(11,4)=$ Zaditen $(11,2)$ $\geq$ Tramelas PF $(10,-1)=$ Patanol $(10,2) \geq$ Rizaben $(9$, $-1) \geq \operatorname{Livostin}(8,-3)$.

HCEC viability was $\geq 80 \%$ for the 1000 -fold dilution of each solution, with the exception of Rizaben (67\%) (Fig. 3). Zepelin was the least toxic and Rizaben exhibited significant toxicity even at low concentrations compared to other eye-drop solutions that contain $0.005 \%$ BAK ( $\mathrm{Za}-$ diten and Ketas). The viability of HCECs when exposed to any of the eye drops was concentration dependent. The order of HCEC viability after exposure to 20-fold dilutions of the eye-drop solutions was approximately the same as the order for the 4 ocular surface cell lines as determined by 


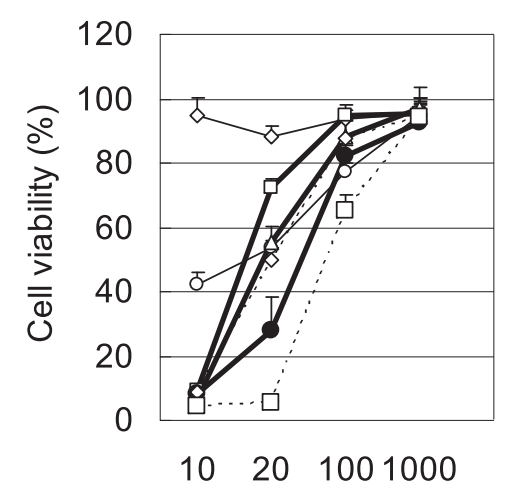

RC-1

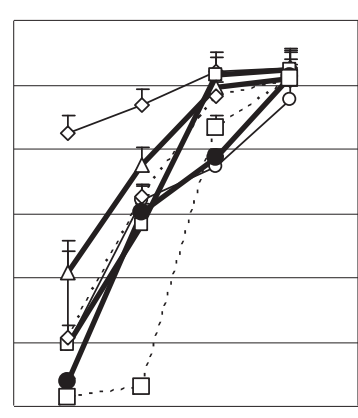

$10 \quad 201001000$

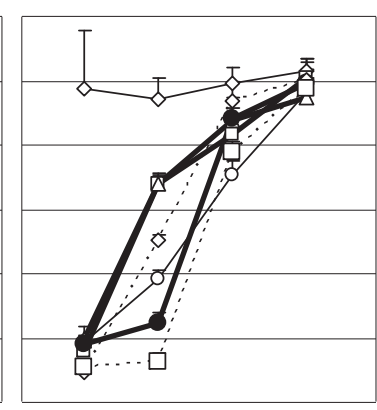

$10 \quad 201001000$

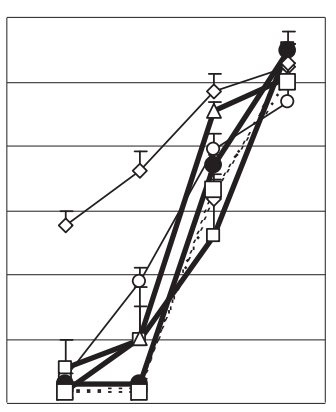

$10 \quad 201001000$

Fold dilution

SIRC

BCE

Chang
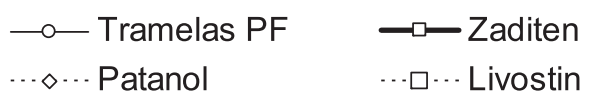

$\multimap-$ Ketas

$\underset{\longrightarrow \text { Zepelin }}{\longrightarrow \text { Rizaben }}$

$\cdots \diamond$... Patanol

- -... Livostin

Fig. 2 Effects of anti-allergic eye drops on the viability of cultured rabbit corneal epithelial cells (RC-1 and SIRC), bovine corneal epithelial cells (BCE), and human conjunctival cells (Chang) after $48 \mathrm{~h}$ exposure.

Data represent the mean \pm standard deviation. Zepelin was the least toxic drug, and Livostin was the most toxic drug. Rizaben was more toxic than other eye drops containing $0.005 \%$ BAK (Zaditen and Ketas). The cell viability score was determined (Table 1), and the order of cell viability was Zepelin $>$ Ketas $=$ Zaditen $\geq$ Tramelas PF $=$ Patanol $\geq$ Rizaben $\geq$ Livostin .

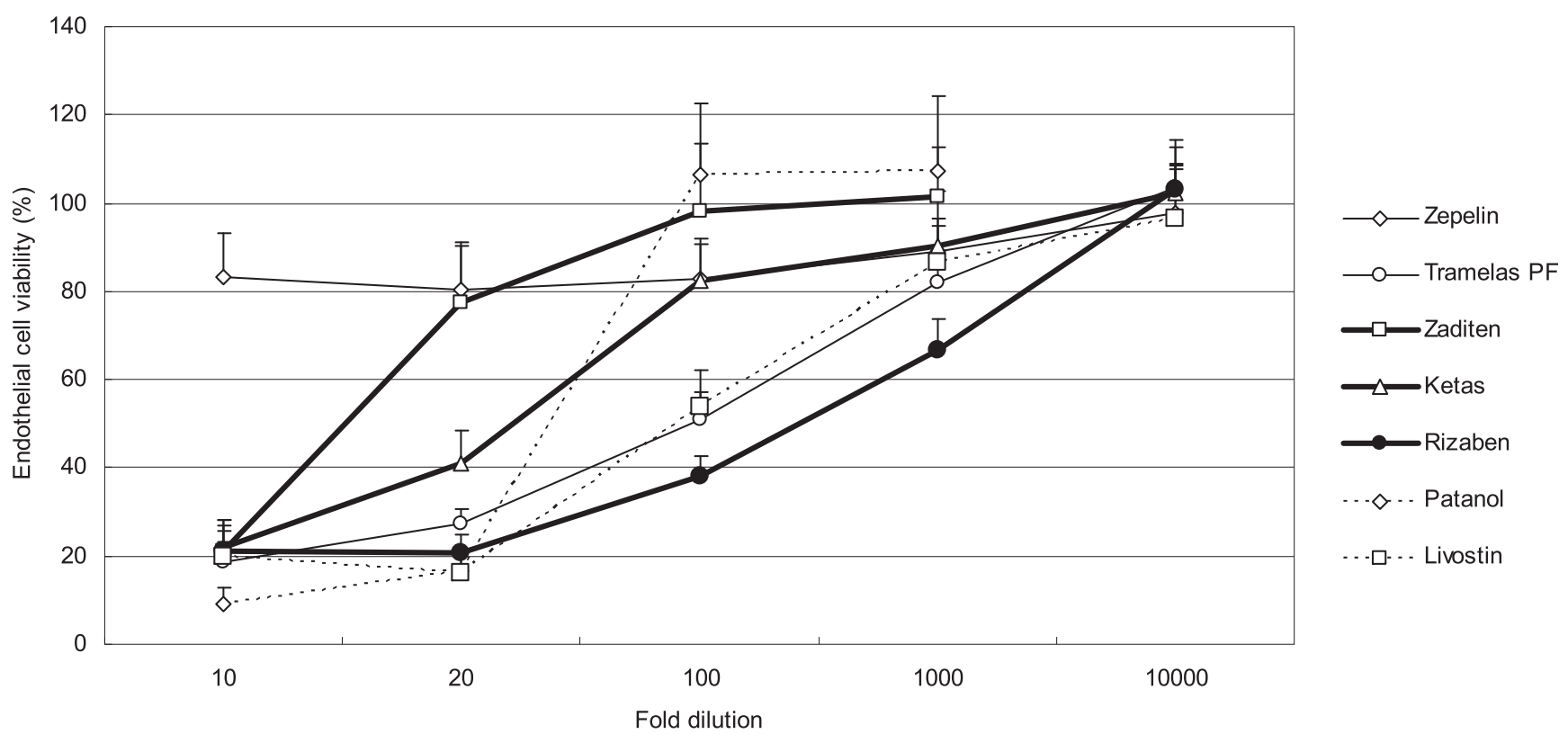

Fig. 3 Effects of anti-allergic eye drops on the viability of cultured human corneal endothelial cells (HCECs) after 48 $\mathrm{h}$ exposure.

Zepelin was the least toxic drug, and Rizaben exhibited significant toxicity even at low concentrations as compared to other eye drops containing $0.005 \%$ BAK (Zaditen and Ketas). Data are the mean \pm standard deviation. 
CVSs. This suggests that HCEC viability is dependent on the concentration of BAK.

We have previously examined the cytotoxicity of multidose Cromoglicate containing preservative (Intal), BAKfree single-dose Cromoglicate (Intal UD), and BAK-free multi-dose Cromoglicate (Cumorol PF) using the same protocol as that of the present study ${ }^{4)}$. Assays of HCEC viability after exposure to 20-fold dilution of drugs yielded $20.1 \pm 5.1 \%$ for Intal, $76.9 \pm 7.9 \%$ for Intal UD, and $75.5 \pm$ $9.4 \%$ for Cumorol PF. As for 4 ocular surface cell lines, the combined results of previous 4 drugs and the present ones indicate the order of cell viability in the drugs (concentration of BAK, CVS50, and CVS40/80) after $48 \mathrm{~h}$ exposure is Intal UD (zero, 4, 4) $\geq$ Zepelin (zero, 4, 3) $\geq$ Cumorol PF (zero, 4, 2) $>\operatorname{Ketas}(0.005 \%, 3,-1)=$ Zaditen $(0.005 \%$, $3,-1) \geq$ Tramelas PF (zero, 2, -2$)=$ Patanol $(0.01 \%, 2$, $-1) \geq$ Rizaben $(0.005 \%, 1,-3)=\operatorname{Intal}(0.01 \%, 1,-3) \geq$ Livostin $(0.015 \%, 0,-4)$. Our results is the same as previously reported by Nakashima ${ }^{11)}$ after $24 \mathrm{~h}$ for a normal rabbit corneal epithelial cell line. Ocular surface cell viability depends upon the concentration of BAK rather than either the content of the active component or its action (i.e., inhibitor of histamine release from mast cells; histamine $\mathrm{H}_{1}$ receptor blocker) with the exception of Rizaben and Tramelas PF (BAK-free). The cell viability in them was often lower than that of drugs containing more BAK (Fig. 2).

We previously determined the CVS50 for 12 anti-allergic eye drop solutions after exposure for 10, 30, and $60 \mathrm{~min}^{3)}$ using the MTT assay and the neutral red assay in the same 4 cell lines as the present study. The order of cell viability was Zepelin $\geq$ Tramelas $\mathrm{PF} \geq$ Cumorol $\mathrm{PF} \geq$ Ketotifen $\mathrm{PF} \geq$ Eyevinal $(=$ Ketas $)=$ Fumarton $(=$ Zaditen $) \geq$ Cumorol $>$ Intal $\geq$ Rizaben $\geq$ Tramelas $\geq$ Patanol $>$ Livostin. This order is essentially in agreement with the inverse of BAK concentration in the drug solutions. A comparison of the results of CVS50 values between short (10, 30, and 60 min) and long (48 h) exposures indicated that Tramelas PF decreased cell viability, whereas Patanol increased it, which does not correspond to the concentration of BAK in each solution. Therefore, we hypothesized that the effect of their active component was not observed with short-term exposure, but could be observed with long-term exposure. Tranilast, which is the active ingredient in Tramelas PF, has an inhibitory effect on cell proliferation ${ }^{12)}$. Clinical and experimental studies have indicated that olopatadine, which is in Patanol, results in mild ocular surface damage ${ }^{13,14)}$. Treatment with Ketas (=Eyevinal) eye drops, which contains Ibudilast, produced higher cell viability than other eye drops with the same BAK concentration (0.005\%) after short- and long-term exposure, which may result from the cytoprotective properties previously observed for Ibudilast $^{15,16)}$.

These studies revealed that HCEC viability is primarily dependent upon the concentration of BAK and not on the action of the drug. The active component in the eye drops may partially contribute to toxicity, which appears to be the case for Tranilast, but whether this is true for the other drugs remains unclear. HCEC toxicity significantly decreased after dilution. Most patients with allergic conjunctivitis do not have extensive ocular surface barrier damage except in severe $\operatorname{cases}^{17)}$, and the actual drug concentration exposed to corneal endothelial cells after transcorneal penetration ranges from a 1,000-fold to a 100,000-fold dilution $^{18-20)}$. The fact sheet provided for Zepelin states that Acitazanolast is undetectable in intraocular tissue immediately after consecutive instillation for $7 \mathrm{~d}$. Therefore, it is unlikely that these drugs could cause endothelial damage except in rare cases because cell viability was $>85 \%$ for most drugs at a 1,000-fold dilution, which is substantially greater than the actual concentration in the anterior chamber of the eye.

One limitation of the present study is that commercial eye drops were used, which contains a mixture of active and adjunct components, making it difficult to determine the effects of individual components. However, an advantage of this approach is that the commercial products are used by patients and therefore our investigation has direct clinical significance.

\section{CONCLUSIONS}

Anti-allergic eye drops were cytotoxic to HCECs. However, damage to HCECs due to the eye drops likely occurs only in rare cases since dilution of the eye drop resulted in markedly lower toxicity. Epithelial cell viability depended mostly on the concentration of BAK, the preservative in the eye drops, rather than on the action of the active ingredients in the eye-drop solution. Zepelin (BAK-free) was the least toxic. Tranilast containing eye drops exhibited more toxicity than eye drops containing more BAK. As such, physicians should be aware of the concentration of BAK in anti-allergic eye drops for examination of ocular surface complications in allergic patients.

\section{References}

1) Baudouin, C. Allergic reaction to topical eyedrops. Curr. Opin. Allergy Clin. Immunol. 5, 459-463 (2005).

2) Baudouin, C.; Labbé, A.; Liang, H.; Pauly, A.; BrignoleBaudouin, F. Preservatives in eyedrops: The good, the bad and the ugly. Prog. Retin. Eye. Res. 29, 312-334 (2010).

3) Ayaki, M.; Taguchi, Y.; Soda, M.; Yaguchi, S.; Iwasawa, A.; Koide, R. Preserved and unpreserved 12 anti-allergic ophthalmic solutions and ocular surface toxicity: In 
vitro assessment in four cultured corneal and conjunctival epithelial cell lines. Biocontrol Sci. in press.

4) Ayaki, M.; Yaguchi, S.; Koide, R.; Iwasawa, A. Human corneal endothelial toxicity of eye drop with and without preservatives. Exp. Clin. Ophthalmol. 36, 553-559 (2008).

5) Ishiyama, M.; Shiga, M.; Sasamoto, K.; Mizoguchi, M.; He, P. A new sulfonated tetrazolium salt that produces a highly water-soluble formazan dye. Chem. Pharm. Bull. 41, 1118-1122 (1993).

6) Mosmann, T. Rapid colorimetric assay for cellular growth and survival: Application to proliferation and cytotoxicity assays. J. Immunol. Methods 65, 55-63 (1983).

7) Ayaki, M.; Soda, M.; Yaguchi, S.; Iwasawa, A.; Koide, R. Cytotoxicity of five fluoroquinolone and two nonsteroidal anti-inflammatory benzalkonium chloridefree eye drops in four corneoconjunctival cell lines. Clinical Ophthalmol. 4, 1019-1024(2010).

8) Ayaki, M.; Iwasawa, A.; Yaguchi, S.; Koide, R. Preserved and unpreserved 12 anti-allergic eye drops and ocular surface toxicity: in vitro assessment in four cultured corneal and conjunctival epithelial cell lines. Biocontrol Sci. 15, 97-102(2010).

9) Ayaki, M.; Iwasawa, A. Cytotoxicity of prostaglandin analogue eye drops preserved with benzalkonium chloride in multiple corneoconjunctival cell lines. Clinical Ophthalmol. 4, 919-924 (2010).

10) Ayaki, M.; Iwasawa, A.; Inoue, Y. Toxicity of antiglaucoma drugs with and without benzalkonium chloride to cultured human corneal endothelial cells. Clinical Ophthalmol. 4, 1217-1222(2010).

11) Nakashima, M.; Nakamura, T.; Teshima, M.; To, H.; Uematsu, M.; Kitaoka, T.; Taniyama, K.; Nishida, K.; Nakamura, J.; Sasaki, H. Breakdown evaluation of corneal epithelial barrier caused by antiallergic eyedrops using an electrophysiologic method. J. Ocul. Pharmacol. Ther. 24, 43-51 (2008).

12) Oshima, T.; Kurosaka, D.; Kato, K.; Kurosaka, H.; Mashima, Y.; Tanaka, Y.; Tajima, S. Tranilast inhibits cell proliferation and collagen synthesis by rabbit corneal and Tenon's capsule fibroblasts. Curr. Eye Res. 20, 283-286 (2000).

13) Lekhanont, K.; Park, C.Y.; Combs, J.C.; Suwan-Apichon, O.; Rangsin, R.; Chuck, R.S. Effect of topical olopatadine and epinastine in the botulinum toxin B-induced mouse model of dry eye. Ocul. Pharmacol. Ther. 23, 83-88 (2007).

14) Dogru, M.; Ozmen, A.; Ertürk, H.; Sanli, O.; Karatas, A. Changes in tear function and the ocular surface after topical olopatadine treatment for allergic conjunctivitis: An open-label study. Clin. Ther. 24, 1309-1321 (2002).

15) Tominaga, Y.; Nakamura, Y.; Tsuji, K.; Shibata, T.; Kataoka, K. Ibudilast protects against neuronal damage induced by glutamate in cultured hippocampal neurons. Clin. Exp. Pharmacol. Physiol. 23, 519-523 (1996).

16) Barkhof, F.; Hulst, H.E.; Drulovic, J.; Uitdehaag, B.M.; Matsuda, K.; Landin, R.; MN166-001 Investigators. Ibudilast in relapsing-remitting multiple sclerosis: a neuroprotectant? Neurol. 74, 1033-1040 (2010).

17) Tanaka, M.; Dogru, M.; Takano, Y.; Miyake-Kawashima, M.; Asano-Kato, N.; Fukagawa, K.; Tsubota, K.; Fujishima, H. The relation of conjunctival and corneal findings in severe ocular allergies. Cornea 23, 464-467 (2004).

18) Fukuda, M.; Takahashi, N. Intraocular penetration of gatifloxacin eye drop in rabbit eye - Calculation of maximum aqueous concentration (AQCmax). Atarashii Ganka 21, 1109-1112 (2004).

19) Fukuda, M.; Sasaki, H.; Ohashi, Y. Intraocular penetration of moxifloxacin eye drop in rabbit eye - Calculation of maximum drug concentration in aqueous concentration (AQCmax). Atarashii Ganka 23, 13531357 (2006).

20) Ellis, P.P.; Pfoff, D.S.; Bloedow, D.C.; Riegel, M. Intraocular diclofenac and flurbiprofen concentrations in human aqueous humor following topical application. $J$. Ocul. Pharmacol. 10, 677-682 (1994). 